\title{
Time-related wettability characteristic of acrylic resin surfaces treated by glow discharge
}

\author{
Nehir Ö zden, DDS, PhD,a Funda Akaltan, DDS, PhD,a, Sefik Suzer, PhD,b and G uneri Akovali, PhD c \\ Faculty of Dentistry, Ankara University; Bilkent U niversity; and Middle East Technical U niversity, Ankara, \\ Turkey
}

\begin{abstract}
Statement of problem. Adhesion and cohesion have important roles in denture retention, and attempts have been made to improve the wettability of the acrylic resin material by surface treatments.

Purpose. This study examined the initial and subsequent wettability of an acrylic resin denture base material treated under air or argon plasma atmosphere before and after exposure to air or distilled water.

M aterial and methods. Acrylic resin specimens were treated with plasma under air or argon atmosphere and were either exposed to air or distilled water for up to 60 days. Wettability characteristics of the acrylic resin specimens were determined by contact-angle measurements after 2 hours and after 60 days. Surface composition of the specimens also was analyzed with $x$-ray photoelectron spectroscopic (XPS) measurements.
\end{abstract}

Results. Statistically significant difference was found between control and each of the plasma treatment groups $(P<05)$. Although the storage condition and storage period caused statistically significant difference on contact angle values $(P<.05)$, atmosphere type did not have any effect on the results $(P>.05)$. XPS spectra of the plasma-treated specimens differed from control specimens only in the $01 \mathrm{~s}$ region with a narrower and more intense peak that could be assigned to $-\mathrm{COH}$ groups. D uring 60 days of exposure, the $\mathrm{O} / \mathrm{C}$ atomic ratios decreased within the first 2 weeks but settled to 0.40 and 0.32 up to 60 days compared with 0.26 for untreated control specimens.

Conclusion. Glow discharge plasma altered the surfaces of the acrylic resin and increased the wettability as shown both by XPS and contact-angle measurements, and plasma treatment seemed to offer a durable (at least up to 60 days) wettability. (J Prosthet D ent 1999;82:680-4.)

\section{CLINICAL IMPLICATIONS}

Obtaining a durable improved wettability from altered acrylic resin surfaces by glow discharge plasma treatment may help to increase denture retention.

A number of forces and factors combine to retain complete dentures in position, such as adhesion, cohesion, interfacial surface tension, mechanical locking into undercuts, peripheral seal, atmospheric pressure, and oral and facial musculature. ${ }^{1-3}$ Adhesion and cohesion play important roles in denture retention. Adhesion of saliva to mucosa and saliva to acrylic resin denture base material, and cohesion of saliva molecules to one another can be enhanced by an impression that provides the most intimate contact with the surface mucosa, and the greatest feasible area coverage. ${ }^{4}$ To achieve this intimate contact, adhesive is usually in liquid form.

Presented at 75th General Session of the International Association of Dental Research, O rlando, Fla., M arch 1997.

associate Professor, Department of Prosthodontics, Faculty of Dentistry, Ankara University.

bProfessor, Department of Prosthodontics, Faculty of Dentistry, Ankara U niversity.

cProfessor, Department of Chemistry, Bilkent U niversity.
Liquid adhesive is more apt to flow easily over the entire surface of the adherent and come in contact with all of the small roughness that may be present. Such a characteristic is referred to as wetting. The better the adhesive flows over, or wets, the surface of the adherent, the more likely it is that adhesion will occur between the 2 . Wettability characteristic of the adhesive depends on the viscosity of the adhesive, the purity of the adherent surface and the shape of the irregularities on the adherent surface. The quantitative measure of the wetting process is taken to be the contact angle (0) that the adhesive makes with the adherent surface. The smaller the contact angle, the greater the wettability.3,5

Because denture base extension is limited by features of the oral anatomy and that there is a limit to the closeness of the tissue fit that can be achieved, only the contact angle for saliva on the denture base is amenable to alteration. ${ }^{5}$ Therefore, various attempts have been made to improve the wettability of the PM M A material by surface treatment rather than vary the material. ${ }^{1,5-7} \mathrm{O}{ }^{\prime} \mathrm{B}$ rien and $\mathrm{R}_{\mathrm{yge}}{ }^{7}$ exposed the sur- 


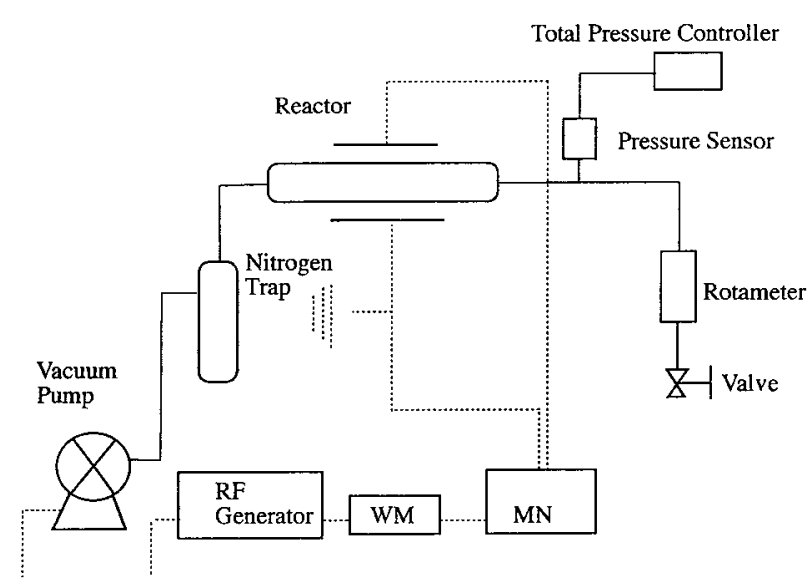

Fig. 1. Diagrammatic representation of glow discharge plasma.

face of acrylic resin to the vapors of water and silicon tetrachloride and reported a significant decrease in the contact angle on acrylic resin of various liquids, including saliva and an apparent 10\% of increase in denture retention. Boucher et al 8 treated mandibular dentures with silicon tetrachloride and increased the amount of retention between mandibular denture and the basal seat tissue.

O ther methods of surface treatment were also used by Gesser and Castaldi, 6 who also used vacuum discharge. H owever, these authors did not assess the contamination effect by the wetting fluid on the acrylic resin surface or test the durability of these various surface treatments. Their results were interesting pointers, but could not be taken as definitive evidence. M urray 5 investigated the effect of exposure to saliva on the acrylic resin material that had been so treated and reported that there was no prospect of improving denture retention by any surface treatment.

The aim of the study was to examine the initial and subsequent wettability of acrylic resin denture, base material treated under air or argon plasma atmosphere before and after exposure to air or distilled water. The time-related wettability characteristic of the plasmatreated acrylic resin surfaces also was observed.

\section{MATERIAL AND METHODS}

Test specimens were prepared from an acrylic resin denture base material ( $M$ eliodent, D ental Bayer Limited Pharmaceuticals D ivision, Berkshire, U.K.) by using heat-compression mold technique. They were treated with plasma under air or argon atmosphere to determine the effect of different plasma atmospheres on the wettability of acrylic resin. Then the specimens were either exposed to air or distilled water for 2 different periods ( 2 hours and 60 days) to observe the durability of plasma treatment.
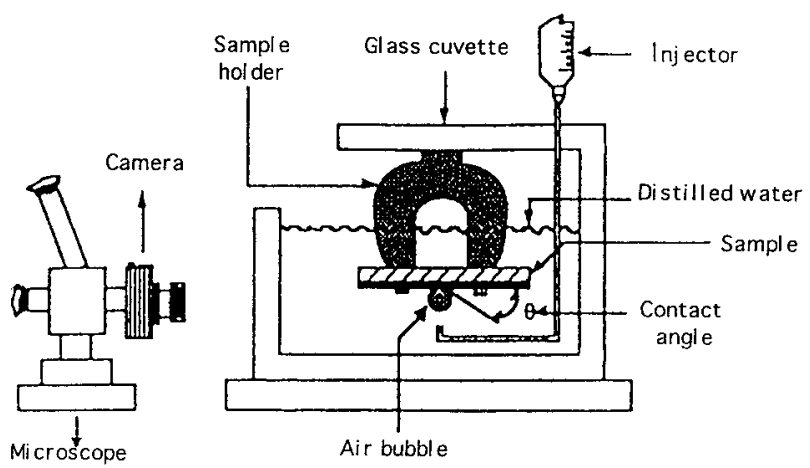

Fig. 2. Schematic view of entrapped air-bubble technique.

With a separator (I solant C.M.S., D e Trey D entsply S.A., Weybridge, U.K.), the 2 parts of the metal denture flask were filled with dental stone (Duralit $S$, D egussa AG, Frankfurt, Germany). After the dental stone set, the 2 portions were separated. Powder and liquid acrylic resin denture base material were mixed and processed according to the manufacturer's recommendations. Polymerized acrylic resin was sectioned into small films with the dimensions of $10 \times 15 \times$ $1 \mathrm{~mm}$ for a total of 54 specimens. Specimens were randomly selected and divided into the following 9 groups: (1) control (C); (2) plasma treated under air atmosphere and left exposed to air for 2 hours (A1); (3) plasma treated under air atmosphere and stored in distilled water for 2 hours (W1); (4) plasma treated under argon atmosphere and left exposed to air for 2 hours (AA1); (5) plasma treated under argon atmosphere and stored in distilled water for 2 hours (AW 1); (6) plasma treated under air atmosphere and left exposed to air for 60 days (A2); (7) plasma treated under air atmosphere and stored in distilled water for 60 days (W2); (8) plasma treated under argon atmosphere and left exposed to air for 60 days (AA2); and (9) plasma treated under argon atmosphere and stored in distilled water for 60 days (AW2).

A small hole was prepared on 1 angle of each of the plasma treatment receiving test specimens by using a round bur, then specimens were washed with distilled water and dried in air.

Plasma treatment for surface modifications was achieved by using a Tegal radiofrequency (rf) plasma system (Tegal Corp, H ayward, Calif.) (Fig. 1). Specimens were placed in the pyrex glass reactor (SchottGen Product, Germany) $(50 \mathrm{~cm}$ length $\times 6.2 \mathrm{~cm}$ in inner diameter) between electrodes by hanging on a glass rod; hence, all surfaces were treated equally in the plasma. Reactor could be evacuated and/ or filled with various gases. T wo copper electrodes on the Pyrex reactor were capacitatively coupled to a rf plasma system consisting of a fixed frequency $(13.56 \mathrm{M} \mathrm{Hz})$ rf gener- 


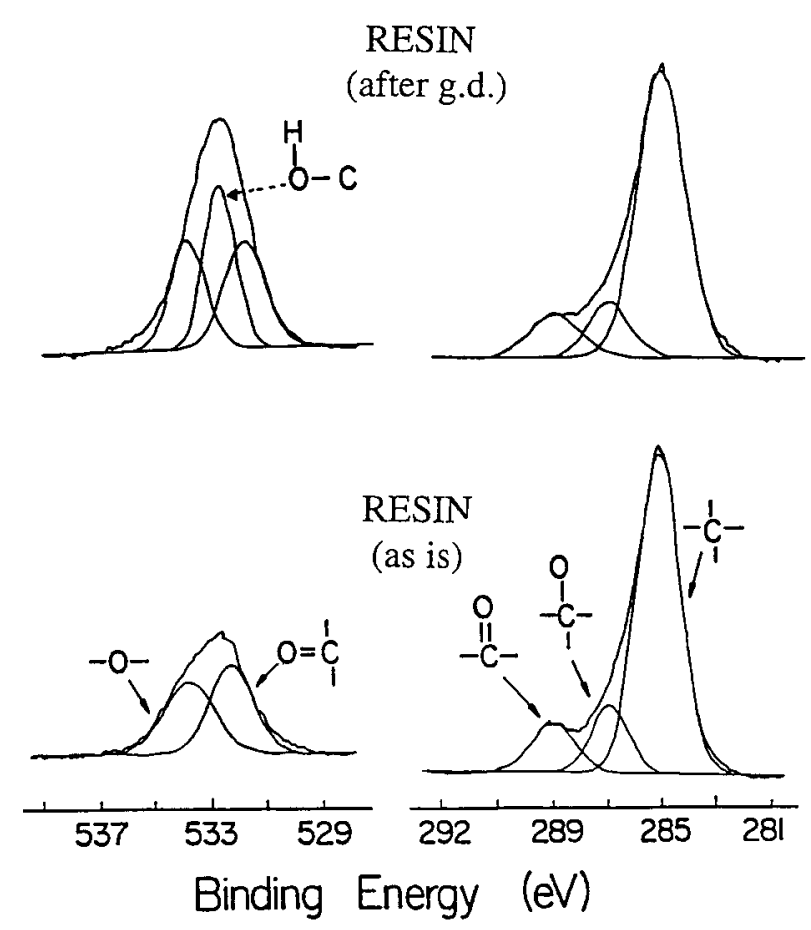

Fig. 3. $01 \mathrm{~s}$ and $\mathrm{C} 1 \mathrm{~s}$ XPS of untreated (control) and glow discharge-treated resin at 90-degree take-off angles. Enhanced $\mathrm{O}$ 1s signal is assigned to $-\mathrm{COH}$.

ator together with an rf power meter and a matching network. D uration of plasma application was 10 minutes and plasma power applied was $10 \mathrm{~W}$.

To determine the wettability of the acrylic resin specimens, contact angles of distilled water were measured on 5 specimens from each experimental group by using entrapped air-bubble technique. ${ }^{9}$ The experimental set up mainly consisted of a glass cuvette filled with double distilled deionized water, a specimen holder, a joint camera-microscope apparatus, and a syringe to deliver the air bubbles to the acrylic resin surface (Fig. 2). Air bubbles on the specimen surface were photographed and calculations were determined according to the following equations:

If $\theta \leq 90$ degrees, then: $\theta=\cos ^{-1}(2 \mathrm{H} /[\mathrm{D}-1])$
If $\theta>90$ degrees: $\theta=180-2\left[\tan ^{-1}(2 \mathrm{H} / \mathrm{D})\right]$

where $\mathrm{H}=$ height of the bubble, and $\mathrm{D}=$ diameter of the bubble.

Surface composition of the specimens was also analyzed by x-ray photoelectron spectroscopy(XPS) measurements using 1 specimen from each experimental group. Duplicate measurements were carried out to ensure reproducibility. XPS measurements were performed on a Kratos ES300 spectrometer (Kratos, M anchester, U .K.) with M gKa x-rays (1253.6 eV) having a background pressure lower than $5 \times 10^{-9} \mathrm{~mm} \mathrm{H} \mathrm{g}$.
Table I. Descriptive statistical values and the results of Duncan's multiple range test

\begin{tabular}{llccc}
\hline G roup & $\mathbf{n}$ & $\overline{\mathbf{x}}$ & SD & Duncan grouping \\
\hline $\mathrm{C}$ & 5 & 63.18 & 4.87 & $\mathrm{~A}$ \\
$\mathrm{~A}_{1}$ & 5 & 51.64 & 3.42 & $\mathrm{~B}$ \\
$\mathrm{~W}_{1}$ & 5 & 46.09 & 5.74 & $\mathrm{~B}$ \\
$\mathrm{AA}_{1}$ & 5 & 51.43 & 3.02 & $\mathrm{~B}$ \\
$\mathrm{AW}_{1}$ & 5 & 51.09 & 5.75 & $\mathrm{~B}$ \\
$\mathrm{~A}_{2}$ & 5 & 51.31 & 5.31 & $\mathrm{~B}$ \\
$\mathrm{~W}_{2}$ & 5 & 44.54 & 4.86 & $\mathrm{~B}$ \\
$\mathrm{AA}_{2}$ & 5 & 46.95 & 2.04 & $\mathrm{~B}$ \\
$\mathrm{AW}_{2}$ & 5 & 45.02 & 2.75 & $\mathrm{~B}$
\end{tabular}

Abbreviations in group column as mentioned in material and methods section.

M eans with the same letter are not significantly different $(P>.05)$.

$\mathrm{n}=\mathrm{N}$ umber of the samples.

$\overline{\mathrm{x}}=$ Mean.

$\mathrm{SD}=$ Standard deviation.

Table II. Results of 2-way ANOVA

\begin{tabular}{lcc}
\hline Source of variation & $\mathbf{F}$ & $\mathbf{P}$ \\
\hline$A$ & 0.401 & .531 \\
$B$ & 5.784 & $.022^{*}$ \\
$C$ & 4.658 & $.039 *$ \\
$A \times B$ & 3.558 & .068 \\
$A \times C$ & 0.065 & .800 \\
$B \times C$ & 0.172 & .681 \\
$A \times B \times C$ & 0.606 & .442 \\
\hline$A$
\end{tabular}

$\mathrm{A}=$ Atmosphere type; $\mathrm{B}=$ storage condition; $\mathrm{C}=$ storage period. $* \mathrm{P}<.05$.

For contact angle measurements, experimental groups were compared by 1-way analysis of variance (AN OVA) and D uncan's multiple range test to determine whether there were any differences in mean values. T wo-way ANO VA was performed among the plasma treatment groups to evaluate the effects of plasma atmosphere type (argon or air), storage condition (air or distilled water), and storage period ( 2 hours or 60 days) on the contact angle values.

\section{RESU LTS \\ Contact angle measurements}

Statistically significant differences were observed between the control and each of the plasma treatment groups $(P<05)$. D escriptive statistical values and the results of D uncan's multiple range test are summarized in Table I. Two-way (Table II) and 3-way ANOVA interactions were not significant $(P>05)$, bivariate and trivariate effects of factors had to be ignored, and main effects in the model were considered. Although the storage condition and storage period caused statistically significant difference on contact angle values $(P<05)$, atmosphere type did not have any effect on the results $(P>.05)$. 


\section{XPS measurements}

XPS spectra recorded at a 90-degree take-off angle of the control and plasma-treated specimens are given in Figure 3. The spectra of the plasma-treated specimens differed only in the first electron level of the oxygen atom $(01 \mathrm{~s})$ region with a narrower and more intense peak that could be curve-fitted to 3 components. The extra peak at $533.0 \mathrm{eV}$ could be assigned to the hydroxyl group bonded to carbon atom $(-\mathrm{COH})$ groups. 10,11

The use of an argon atmosphere instead of air during plasma treatment resulted in very similar features in XPS spectra of the treated specimens. To assess the durability of the plasma treatment, the XPS oxygen to carbon $(\mathrm{O} / \mathrm{C})$ atomic ratios of the specimens left in air and the ones placed in distilled water have been followed up to 60 days after plasma treatment (Fig. 4). Both in the specimens left in air and in distilled water, the $0 / \mathrm{C}$ ratios decreased within the first 2 weeks but settled to 0.40 and 0.32 up to 60 days for air and distilled water specimens compared with 0.26 for untreated control specimens.

\section{DISC U SSION}

The role of adhesive action of a thin film of saliva between the palate and surface of a complete denture has been identified as one of the principal sources of denture retention. ${ }^{7}$ There is little retention without the existence of a liquid meniscus and surface tension is essential to form the seal that keeps air away from the denture and tissue surfaces. ${ }^{1}$ Both surface tension and viscosity of the liquid affect the magnitude of the adhesive or retentive force. With low viscosity of saliva and water, the surface tension factor predominates. ${ }^{7} \mathrm{C}$ raig et al12 measured the contact angle of water and saliva on acrylic resin and polystyrene and observed high contact angle values, which mean poor wettability on these resins because of their low surface energies.

Glow discharge (plasma) treatment of polymer surfaces and plasma polymerization has been used for many years ${ }^{13}$ and several investigators ${ }^{5,6}$ have attempted to use this method to improve the wettability of acrylic resin. In the plasma, there are energetic-free electrons produced at ambient temperatures, which can collide with polymer surfaces and gas molecules around to form active species both in the gas phase and on the substrate surfaces. ${ }^{14}$ The initial wettability measurements of the attempted treatment of acrylic resin by glow discharge revealed that an apparent success could be achieved in decreasing the contact angle values compared with untreated specimens.

XPS is a surface-sensitive technique and has been used extensively for elucidating chemical composition of various kinds of materials, including polymers. ${ }^{10,11}$ Any element, besides hydrogen $(H)$, can be detected within the $100 \mathrm{~A}$ depth from the surface with chemical-

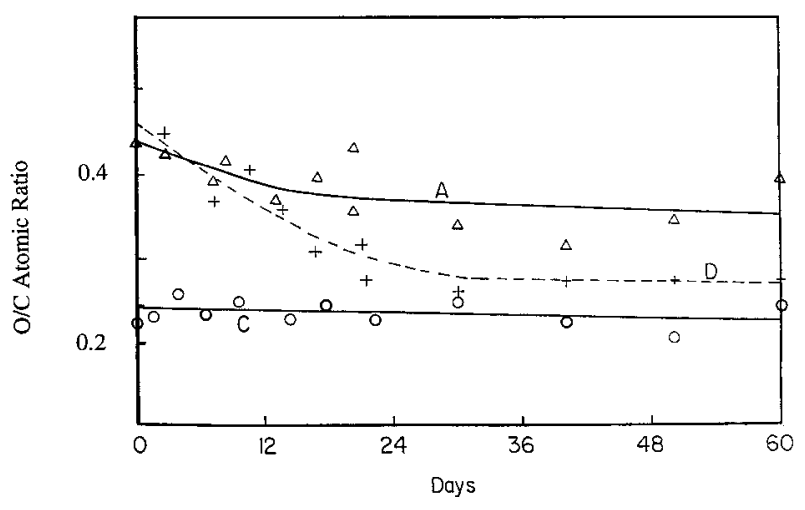

Fig. 4. M easured $O / C$ atomic ratios of plasma-treated specimens left in air (A) and placed in distilled water (D) up to period of 60 days. Measurements in control specimens not exposed to plasma (C) are also included.

state information. Exposure to glow discharge both in air and argon atmosphere improved the wettability of acrylic resin material in our study. XPS measurements indicated that glow discharge altered the acrylic resin surface and improvement in the wettability of acrylic resin material might be attributed to the extra peak of $-\mathrm{COH}$ groups attained only in the 01 s region. 10,11

XPS spectra recorded at a 90-degree take-off angle of the control and plasma-treated specimens are similar to the high-resolution spectra of PM M A compiled by Beamson and Briggs, 11 except for the $\mathrm{O} / \mathrm{C}$ atomic ratio. Although their high resolution spectrum assigned 4 carbons, we can neither resolve nor successfully differentiate between different hydrocarbon C1s peaks using curve-fitting. Therefore, the $\mathrm{C} 1 \mathrm{~s}$ region was fitted into only 3 peaks corresponding to $\mathrm{CH}, \mathrm{C}-\mathrm{O}$, and $\mathrm{C}=0$ groups. The $\mathrm{O} 1 \mathrm{~s}$ region is fitted to 2 peaks corresponding to etheric and esteric oxygens. The $\mathrm{O} / \mathrm{C}$ atomic ratio in our control specimens is 0.26 , which is different from 0.4 expected for pure PM M A. This deviation probably stems from the additives introduced through the various processes in preparation and/ or molding and also can be attributed to the acrylic resins used in dentistry as not being a pure PM M A material.

Solid surfaces in the oral cavity do not remain free of adsorbed macromolecular compounds for more than a few seconds. 15 In addition, wettability of untreated acrylic resin can almost instantly be altered on contact with saliva. ${ }^{16}$ Therefore, surface treatment of acrylic resin was evaluated after the exposure of the treated acrylic resin surface to air and distilled water. Glow discharge plasma treatment seemed to offer a durable (at least up to 60 days) wettability as also evidenced by XPS measurements. M urray ${ }^{5}$ also reported an effective decrease in the contact angle values to near zero by the exposure of the PM M A to a low-pressure electrical discharge in water vapor and air, but unavoidable contam- 
ination effect was reported after the exposure to saliva. Murray 5 concluded that the denture retention could not be improved by any surface treatment. $D$ ifferences between our results and those of Murray's study may be due to the different plasma treatments that are known to be strongly dependent on various experimental parameters.

$\mathrm{N}$ o contamination effect evidenced on the treated acrylic resin surfaces was a surprising and promising result, but the glow discharge surface treatment of acrylic resin material should still be tested under clinical conditions before considering as a definite alternative for improving denture retention.

\section{CONCLUSION}

Glow discharge plasma altered the surfaces of the acrylic resin and increased the wettability as shown both by XPS and contact-angle measurements and plasma treatment seemed to offer a durable (at least up to 60 days) wettability.

\section{REFERENCCS}

1. Boucher CO, Hickey JC, Zarb GA. Prosthodontic treatment for edentulous patient. 7th ed. St Louis: Mosby; 1975.

2. Lindstrom RE, Pawelchak J, Heyd A, Tarbet WJ. Physical-chemical aspects of denture retention and stability: a review of the literature. J Prosthet Dent 1979;42:371-5.

3. Phillips RW. Elements of dental materials. 4th ed. Philadelphia: WB Saunders; 1984.

4. Sharry JJ. Complete denture prosthodontics. 3rd ed. New York: McGraw Hill; 1974.

5. Murray MD. Investigation into the effectiveness of surface treatment on poly(methyl methacrylate) when exposed in the mouth. J Prosthet Dent 1988;59:368-73.
6. Gesser HD, Castaldi CR. The preparation and evaluation of wetting dentures for adhesion and retention. J Prosthet Dent 1971:25:236-43.

7. O'Brien WJ, Ryge G. Wettability of poly-(methyl methacrylate) treated with silicon tetrachloride. J Prosthet Dent 1965;15:304-8.

8. Boucher LJ, Ellinger C, Lutes M, Hickey JC. The effects of a microlayer of silica on the retention of mandibular complete dentures. J Prosthet Dent 1968;19:581-6.

9. Andrade JD, King RR, G regonis DE. Contact angle at the solid-water interface. J Colloid Interface Sci 1979;72:488-91.

10. Lopez GP, Castner DG, Ratner BD. XPS $01 \mathrm{~s}$ binding energy of polymers containing hydroxyl, ether, ketone and ester groups. Surf Interface Anal 1971;16:267-72.

11. Beamson G, Briggs D. High resolution XPS of organic polymers. Chichester: John Wiley; 1992.

12. Craig RG, Berry GC, Peyton FA. Physical factors related to denture retention. J Prosthet Dent 1960;10:459-67.

13. Akovali G. Plasma polymerization of ethane and some properties of plasma polymerized ethane as a protective coat. J Appl Polym Sci 1986: 32:4026-42.

14. M orosoff N, Crist B, Baumgarmer M, H su T, Yasuda H. Free radicals resulting from plasma polymerization and plasma treatment. J Macromol Sci Chem 1976;3:451-71.

15. Baier RE. Applied chemistry at protein interfaces. Adv Chem Ser 1975; 145:1.

16. Murray MD. Investigation into the wettability of poly(methyl methacrylate) in vivo. J Dent 1986;14:29-33.

Reprint requests to:

Dr Funda AKaltan

KonUtKent 2, A 7 Blok, Daire No: 13

QAYYOLU

06530 ANKARA

TURKEY

FAX: (90)312-2123954

Copyright $\odot 1999$ by The Editorial Council of The Journal of Prosthetic Dentistry.

$0022-3913 / 99 / \$ 8.00+0 . \quad 10 / 1 / 100244$

\section{R eceive T able of Contents by $E$-mail}

To receive the table of contents by e-mail, sign up through our Web site at http:/ / www.mosby.com/ prosdent Choose E-mail Notification.

Simply type your e-mail address in the box and click the Subscribe button.

Alternatively, you may send an e-mail message to majordomo@mosby.com. Leave the subject line blank and type the following as the body of your message:

subscribe prosdent_toc

You will receive an e-mail to confirm that you have been added to the mailing list.

$\mathrm{N}$ ote that table of contents e-mails will be sent out when a new issue is posted to the Web site. 